\title{
Sınıf Öğretmenlerinin Eğitim Bilişim Ağı Televizyon Kanalı (EBA TV) Üzerinden Yapılan Uzaktan Eğitime İlişkin Görüşlerinin İncelenmesi
}

\author{
Mahmut Onur GEZEN \\ Milli Eğitim Bakanlı̆̆ \\ mahmutonurgezen12@gmail.com \\ ORCID ID: 0000-0001-8704-8952 \\ Akın EFENDİOĞLU \\ Çukurova Üniversitesi \\ eakin@cu.edu.tr \\ ORCID: 0000-0001-6756-7405
}

Araştırma Makalesi

Geliş Tarihi: 11.04.2021

Revize Tarihi: 29.10 .2021

DOI: $10.31592 /$ aeusbed.913343

Kabul Tarihi: 18.11 .2021

\section{Atıf Bilgisi}

Gezen. M. O. ve Efendioğlu, A. (2021). Sınıf öğretmenlerinin Eğitim Bilişim Ağı Televizyon Kanalı (EBA TV) üzerinden yapılan uzaktan eğitime ilişkin görüşlerinin incelenmesi. Ahi Evran Üniversitesi Sosyal Bilimler Enstitüsü Dergisi, 7(3), 776-791.

\section{ÖZ}

$\mathrm{Bu}$ araştırmanın amacı, ilkokul öğrencilerine yönelik olarak Eğitim Bilişim Ağı televizyon kanalında (EBA TV) yapılan uzaktan eğitimle ilgili sınıf öğretmenlerinin görüşlerini incelemektir. Araştırma nitel araştırma yöntemi kullanılarak durum çalışması deseninde tasarlanmıştır. Veriler, Türkiye'nin farklı bölgelerinde görev yapan 48 sınıf öğretmeninin katılımıyla çevrimiçi iletişim araçları kullanılarak toplanmıştır. Katılımcıların yanıtları içerik analizi ile çözümlenerek kodlar ve temalar oluşturulmuş ve doğrudan alıntılarla desteklenmiştir. Araştırma sonuçlarına göre, öğretmenlerin çoğu EBA TV'de yayınlanan derslerde öğretmenin aktif öğrencinin pasif olması sebebiyle yöntem ve tekniği sınırlı bulduğunu; öğrencilerin bireysel farklılıkları dikkate alınmadığı için kazanımlara istenen düzeyde ulaşılamayacağını; derslerin etkililiğinin artması için somutlaştırıcı ve motive edici etkinliklerin çoğaltılması gerektiğini; etkili bir ölçme değerlendirme sistemi kurulmasının önemli olduğunu ve öğretmenlerin deneyimleri arttıkça uzaktan eğitimle işlenen derslerin kalitesinin yükseleceğini belirtmişlerdir. Bu bağlamda, uzaktan eğitim derslerinin niteliği artırılarak yıl boyu örgün eğitime destek olarak yayınlanmaya devam etmesi oldukça önemli olduğu söylenebilir.

Anahtar Kelimeler: EBA TV, ilkokul, öğretmen görüşleri, uzaktan eğitim.

\section{Investigating Views of Classroom Teachers on Distance Education Implemented through the Education Information Network Television Channel (EBA TV)}

\begin{abstract}
The aim of this research is investigating the views of classroom teachers on distance education broadcast on the Educational Information Network television channel (EBA TV) for Primary School students. This research was conducted in a case study design using qualitative research method. Data was collected using online communication tools with the participation of 48 classroom teachers working in different regions of Turkey. The views of the participants were analyzed with content analysis, codes and themes were created and supported with direct quotations. According to the results, most of the teachers found that the method and technique used in the course on EBA TV were very limited as the teacher was active and the student was passive. Since the individual differences of the students are ignored, the goals will not be achieved at the desired level; Concretizing and motivating activities should be increased in order to increase the effectiveness of the courses; They were stated that the importance of establishing an effective measurement and evaluation system and also depending on teachers' experience of distance education, the quality of the courses will improve. In this context, it can be said that it is very important to increase the quality of distance education courses for supporting formal education system via distance education throughout the year.
\end{abstract}

Keywords: EBA TV, primary school, teachers' views, distance education.

\section{Giriş}

Geçmişten günümüze toplum yapısının değişmesiyle birlikte eğitim anlayışı da değişip gelişmektedir. Geleneksel eğitim anlayışında öğretmen ve öğrenci aynı zaman ve mekân içerisinde bulunması gerekirken günümüz şartlarında "uzaktan eğitim" düşüncesiyle böyle bir zorunluluk ortadan kalkmıştır. Uzaktan eğitim, öğretmen ve öğrencinin bir arada bulunmadığı, zaman ve mekân sınırının olmadığı eğitim türüdür (Elcil ve Şahiner, 2014). Baki (2007) uzaktan eğitimi, örgün eğitim sürecinin 
sınıflarda devam etmesinin imkansızlaştı̆̆ durumlarda öğretmen ve öğrencinin etkileşim içerisinde ders işlemeye devam ettiği öğretim yöntemi olarak tanımlamıştır.

Uzaktan eğitim, eş zamanlı (senkron) ve eş zamanlı olmayan (asenkron) şeklinde iki farklı yöntemle uygulanmaktadır. Eş zamanlı eğitim, öğretmen ve öğrencinin eş zamanlı olarak farklı ortamlarda bir araya gelmesiyle oluşturulan sanal sınıflarda gerçekleşmektedir (Işsk, Karacı, Özkaraca ve Biroğul, 2010). Eş zamanlı eğitim ortamlarında öğretmen ve öğrenci etkileşim içerisinde ders işleyebilmektedir (Toker Gökçe, 2008). Öğretmen ve öğrenci iletişimiyle motivasyon arasında doğrusal bir ilişki olduğu düşünülürse (Uçgun, 2013) eş zamanlı eğitimde öğrencinin daha istekli ve başarılı olacağı söylenebilir. Branon ve Essex'in (2001) yaptıkları çalışmada senkron eğitimde etkileşimin olmasıyla beyin firtınası, soru cevap, tartışma gibi fikir üretici etkinliklerin yapılabildiği ve bu sayede klasik örgün eğitime çok benzediğini vurgulamışlardır.

Eş zamanlı olmayan eğitim, öğretmen ile öğrenci arasında zaman ve mekân sınırı olmadan birbirinden bağımsız gerçekleştirdiği derslerdir (Şen, Atasoy ve Aydın, 2010). Bu eğitim türünde doğrudan bir etkileşim olmadığı için özellikle ilkokul öğrencilerinin olumsuz etkilendiği söylenebilir. Çünkü somut işlemler dönemindeki ilkokul öğrencilerinin öğretmenleriyle iletişime girerek duygusal anlamda ve materyaller kullanılarak görsel anlamda desteklenmesi gerekmektedir (Ceylan, 2008; Fidan, 2008; Sünbül, 2008; Yapıc1, 2004). Böylece birden çok duyu organına hitap edileceğinden öğrenme kalıc1 hale gelecektir (Ocak, Islak ve Ocak, 2015; Okatan, 2010). Bununla birlikte Ergüney (2015) ve Yıldız (2011) yaptıkları araştırmada öğrencinin istediği kadar dersi tekrar ederek kendi öğrenme hızında ilerlemesini eş zamanlı olmayan eğitimin avantajları arasında görmüşlerdir.

Avantaj ve dezavantajlarının dışında günümüzde meydana gelen bazı gerekçeler uzaktan eğitimi zorunlu kılmaya başlamıştır (Deveci, 2019). Bu gerekçelerin başında doğal afetler (deprem, sel, heyelan...vb) gelmektedir. Doğal afetlerin meydana geldiği bölge veya ülkelerde hayat şartlarıyla birlikte eğitim süreci de olumsuz etkilenmektedir. Fakat toplumlar kesintisiz eğitime önem verdiği için tüm şartlarda eğitimin devam etmesini istemektedir. Böyle zamanlarda eğitimin devamlılığı ise alternatif eğitim metodu olan uzaktan eğitim yoluyla gerçekleştirilmektedir (Kılınç, 2015).

Son yıllarda tüm insanlığı etkisi altına alan ve yaşamı olumsuz yönde etkileyen Covid-19 salgını nedeniyle birçok ülkede olduğu gibi Türkiye'de de örgün eğitime ara verilerek zorunlu uzaktan eğitime geçilmiştir. Uzaktan eğitimin eş zamanlı olmayan boyutunda zaman ve mekândan bağımsız olunması bu kararın alınmasında en önemli etkenlerden biridir. Böylece öğrenci ve öğretmenler arasında hastalığın yayılması önlenecek ve eğitim süreci sağlıklı bir şekilde devam edecektir. Bu bağlamda eğitim öğretim sürecinin kesintisiz devam etmesi amaciyla EBA TV kanalı kurulmuş ve tüm sınıf kademelerinde ders anlatımları yayınlanmıştır. Ders planlamasına bakıldığında, ilkokul kademesinde derslerin süreleri ortalama yirmi dakika ve günde iki ders olacak şekilde uygulanmaktadır. Ders saatleri dışında gün içinde aynı derslerin yayınları tekrar verilerek dersi izleyen veya izleyemeyen öğrencilere tekrar etme firsatı sunulmaktadır. Temel derslerle birlikte öğrencilerin duyuşsal ve devinişsel iyi oluşlarını sağlamak amacıyla spor ve rehberlik saatleri de düzenlenmektedir.

EBA TV’nin güçlü yanları olmakla birlikte bazı sınırlılıkları da göze çarpmaktadır. Özellikle benimsenen ilerlemeci eğitim felsefesinin temel aldığı yaparak yaşayarak öğrenme anlayışının uygulama sürecine yansımadığı görülmektedir. Bununla birlikte eğitim sisteminin açık sistem olma özelliğini sağlayan ölçme değerlendirme süreci kesintiye uğramaktadır. Ayrıca yavaş veya hızlı öğrenen ayrımı yapmadan derslerin tek tip işlenmesi öğrenciler arasında bireysel farklılıkların dikkate alınmadığını göstermektedir. Bu bağlamda öğretmen ve öğrencilerin EBA TV'nin güçlü ve zayıf boyutlarını değerlendirerek sürece karşı olumlu/olumsuz bir bakış açısı oluşturacakları düşünülmektedir. Uzaktan eğitimde başarıya ulaşabilmek için öğretmen ve öğrencilerin uzaktan eğitime karşı olumsuz algılarını değiştirmek gerekmektedir (Telli ve Altun, 2020). Buradan hareketle öğretmenlerin EBA TV'de yayınlanan uzaktan eğitime yönelik algılarının ortaya çıkarılması uygulamanın başarıya ulaşmasında etkili olacağı düşünüldüğünde bu çalışma önem arz etmektedir. 
Salgın sonrası uzaktan eğitimle ilgili yapılan çalışmalar incelendiğinde (Afşar ve Büyükdoğan, 2020; Aydın, 2020; Coşkunserçe ve İşçitürk, 2019; Çakın ve Akyavuz, 2020; Doğan ve Koçak, 2020; İnci Kuzu, 2020; Öztürk ve Çetinkaya, 2021; Yıldız ve Bektaş, 2020) ilkokul kademesine yönelik çalışmaların yetersiz olduğu göze çarpmaktadır. Fakat ilkokul öğrencileri bilişsel, duyuşsal ve psikomotor özelliklerindeki sinırlılıklar nedeniyle uzaktan eğitimde en fazla zorlanan gruplar arasındadır (Szente, 2020). Bu nedenle ilkokul öğrencilerinin uzaktan eğitimde yaşadığı sorunların sınıf öğretmenleri gözünden tespit edilmesi hem uzaktan eğitim programını hazırlayanların farkındalıklarını artıracak hem de nitelikli eğitim içerikleri hazırlanmasına katkı sağlayacaktır. Ayrıca bu çalışmanın EBA TV'de ders işleyen diğer branş öğretmenleri için rehber olacağı ve bundan sonra yapılacak benzer çalışmalara 1şık tutacağı düşünülmektedir.

\section{Araştırmanın Amacı}

Bu araştırmanın genel amacı, EBA TV üzerinden ilkokul öğrencilerine yönelik yapılan uzaktan eğitime ilişkin sınıf öğretmenlerinin görüşlerini çeşitli değişkenlere göre incelemektir. Bu genel amaç doğrultusunda aşağıdaki sorulara yanıt aranmıştır.

1. EBA TV de işlenen derslerde öğretmenlerin öğretim sürecinde kullandıkları yöntem-tekniklerin etkililiğine ilişkin görüşleri nelerdir?

2. EBA TV de uzaktan eğitim yoluyla işlenen derslerde, öğretmenlerin, öğrencilerin kazanımlara ulaşabilmelerine ilişkin görüşleri nelerdir?

3. EBA TV de yayınlanan eğitimlerin etkisini arttırmak için neler yapılması gerektiğine ilişkin öğretmen görüşleri nelerdir?

4. EBA TV de uzaktan eğitim yoluyla işlenen derslerde öğretmenlerin kullandıkları ölçme değerlendirme yaklaşım ve araçları nelerdir?

\section{Yöntem}

$\mathrm{Bu}$ bölümde araştırmanın modeli, çalışma grubu, veri toplama süreci ve verilerin analizi açıklanmıştır.

\section{Araştırma Modeli}

EBA TV üzerinden 2020-2021 eğitim öğretim yılında yapılan uzaktan eğitime ilişkin sınıf öğretmenlerinin görüşlerini belirlemek amacıyla yürütülen bu çalışmada, nitel araştırma yöntemi kullanılmıştır. Nitel araştırma; gözlem, görüşme ve doküman analizi gibi nitel veri toplama yöntemlerinin kullanıldığı algıların ve olayların doğal ortamda gerçekçi ve bütüncül bir biçimde ortaya konmasına yönelik nitel bir sürecin izlendiği araştırma biçimidir (Yıldırım ve Şimşek, 2013). Bununla birlikte araştırmada uzaktan eğitime ilişkin yaşanan sorunlar, derslerin etkisinin artırılması için çözüm önerileri ve bundan sonraki süreçte uzaktan eğitimin nasıl olması gerektiği derinlemesine incelendiğinden durum çalışması deseni kullanılmıştır. Durum çalışması araştırılan duruma müdahale etmeden derinlemesine inceleme, anlama ve betimleme imkânı sağladığından konuyla ilgili birey, toplum ya da katılımcı hakkında çıkarımlar yapma firsatı sunar (Akar, 2019; Merriam, 2013; Patton, 2018). Ayrıca durum çalışması türlerinden tek durum deseni kullanılmışıtır. Tek durum desenlerinde, isminden de anlaşılabileceği gibi, tek bir analiz birimi (bir birey, bir kurum, bir program, bir okul, vb.) vardır (Yıldırım ve Şimşek, 2013). Bu çalışmada ise analiz birimi olarak EBA TV'de yayınlanan derslerin ele alınması tek durum desenine uygunluğunu ortaya koymaktadır. Diğer yandan, durum çalışmalarında veri çeşitlemesine gidilmesi önerilmekle birlikte, Covid-19 pandemisi nedeniyle, sadece görüşme yoluyla veri toplanmış olması araştırmanın temel sınırlılığıdır. Bu bağlamda analizler, toplanan veriler doğrultusunda gerçekleştirilerek çıkarımlarda bulunulmuştur.

\section{Çalışma Grubu}

Araştırmanın çalışma grubunu EBA TV derslerini takip eden devlet ve özel okul öğretmenleri oluşturmaktadır. Katılımcıların belirlenmesinde mümkün olan en fazla çeşitliliğe ulaşmak amacıyla maksimum çeşitlilik örneklemi kullanılmıştır. Nitel araştırmalarda çalışma grubunda çeşitliliğe 
ulaşılmak istenmesinin nedeni farklı durumlar arasında benzer temalara ulaşabilmektir (Yıldırım ve Şimşek, 2013). Araştırmaya toplam 74 öğretmen gönüllü olarak katılmıştır. Katılımcılara, veri toplamak amacıyla hazırlanan elektronik form, sosyal ağlar ve çevrimiçi iletişim araçları aracılığıyla duyurulmuştur. Ancak 74 katılımcı arasında görüşme formundaki soruları boş bırakan ya da cevap vermeyen öğretmenlerin görüşleri dikkate alınmamış, görüşme formunu eksiksiz dolduran 48 öğretmenin görüşleri analiz edilmiştir. Çalışmaya katılan sınıf öğretmenlerine ilişkin demografik bilgiler Tablo 1'de sunulmuştur.

Tablo 1

Çalışma Grubuna İlişkin Demografik Veriler

\begin{tabular}{lll}
\hline Çalşsma Grubu & f & \% \\
\hline Cinsiyet & & \\
Erkek & 28 & 58 \\
Kadın & 20 & 42 \\
Kıdem & & \\
$0-5$ & 14 & 29 \\
$6-10$ & 14 & 29 \\
$11-20$ & 15 & 31 \\
21 ve üstü & 5 & 10 \\
Çalışa Yeri & & \\
Şehir Merkezi & 25 & 52 \\
Köy & 14 & 29 \\
İlçe & 9 & 19 \\
Mezuniyet & & \\
Lisans & 43 & 90 \\
Yüksek lisans & 5 & 10 \\
Uzaktan Eğitim Tecrübesi & & 13 \\
Var & 6 & 88 \\
Yok & 42 & \\
\hline
\end{tabular}

Tablo 1 incelendiğinde araştırmaya katılan öğretmenlerin \%58'inin erkek \%42'sinin kadın öğretmenlerin oluşturduğu ve en fazla (\%31) 11-20 y1l kıdem sahibi öğretmenlerin katıldığ görülmektedir. Bununla birlikte \%90’1 lisans mezunu olan katılımcıların şehir merkezi, köy, ilçe gibi çeşitli yerleşim yerlerinde çalıştıkları belirlenmiştir. Ayrıca katılımcı öğretmenlerin \%88'i herhangi bir uzaktan eğitim vermemişken \%13'ü uzaktan eğitim tecrübesine sahip olduğu tespit edilmiştir.

\section{Veri Toplama Aracı}

Araştırmanın verileri, Covid-19 nedeniyle örgün eğitime ara verilmesi ve öğretmenlerle okullarda yüz yüze görüşme firsatı olmamasından dolayı Google form isimli çevrimiçi web sitesi üzerinden katılımcılara gönderilen açık uçlu görüşme sorularıyla toplanmıştır. Görüşme sorularını belirleme sürecinde alanyazın taranarak soru havuzu oluşturulmuştur. Belirlenen sorulara ilişkin uzman görüşüne (Eğitim programları alanında bir Doç. Dr., Sınıf öğretmenliği alanında bir Dr. ve en az yedi yıl deneyime sahip iki sınıf öğretmeni) başvurulmuştur. Uzman görüşleri doğrultusunda bazı sorular elenmiş, bazı sorular ise yeniden revize edilerek görüşme formu son halini almıştır. Yapılan düzenlemeyle birlikte geliştirilen form iki bölümden meydana gelmektedir. İlk bölüm araştırmaya katılan sınıf öğretmenlerinin kişisel özelliklerini tespit etmek amacıyla beş sorudan, ikinci bölüm ise sınıf öğretmenlerinin EBA TV'de karşılaştığı sorun ve çözüm önerilerini belirlemek amacıyla beş açık uçlu sorudan oluşmaktadır. 


\section{Verilerin Toplanması ve Analizi}

Katılımcıların derslerle ilgili görüşlerini ortaya koyabilmek için yöneltilen açık uçlu sorulardan elde edilen veriler bilgisayar ortamına aktarılarak çözümlenmiştir. Analiz sürecinde takip edilen işlem basamakları aşağıda verilmiştir.

1) Verilerin kodlanmas1

2) Temaların bulunmas

3) Kodların ve temaların düzenlenmesi

4) Bulguların tanımlanması ve yorumlanmasıdır

Nitel araştırmalarda veri analizi süreci ilk olarak görüşme dökümlerini okumakla başlar (Merriam, 2013). Bu nedenle görüşme verileri toplandıktan sonra genel bir ön okuma yapılmıştır. Daha sonra anlamlı yapıların bir araya getirilmesiyle kodlar ve temalar oluşturulmuş, bulgular bu bağlamda yorumlanmıştır.

\section{Geçerlik ve Güvenirlik}

Merriam (2013), nitel bir araştırmada geçerlik ve güvenirliğinin sağlanabilmesi amacıyla sekiz farklı strateji önermektedir. Bunlar; çeşitleme, katılımcı doğrulaması, veri toplama aşamasında yeterli ve uygun katılım, araştırmacının konumu, uzman incelemesi, denetleme tekniği, zengin betimleme ve azami çeşitliliktir. $\mathrm{Bu}$ araştırmada, önerilen yöntemlerden, uzman incelemesi ve zengin betimleme stratejilerinden yararlanılmıştır. Yapılan analizin güvenirliğini belirlemek için araştırmacının dışında iki bağımsız kodlayıcının (Sınıf öğretmenliği alanında bir Dr. ve eğitim programları alanında bir Doç. Dr.) bir grup görüşme metni üzerinden (toplam görüşmelerin \%20'si) oluşturdukları kodlar arasındaki uyum incelenmiştir. Kodlayıcılar 20 kod üzerinde benzer açıklamalara sahip olarak fikir birliği sağlamış, 2 kod üzerinde ise fikir ayrılığı yaşamışlardır. Bu bağlamda, Miles ve Huberman'ın (1994) formülü dikkate alınarak [Kodlayıcı uyumu=(Fikir birliği/Fikir birliği+Fikir ayrıllı̆ı)x100] kodlayıcı uyumu $\% 90$ olarak hesaplanmıştır. Bu sonuç veri analizinin yeterli güvenirlik düzeyine sahip olduğunu göstermektedir. Ayrıca, oluşturulan kodların uygunluğu bir alan uzmanı (Dr. Sınıf Öğretmeni) tarafından değerlendirilmiştir. Kodlara ilişkin açıklamalar yapılırken doğrudan alıntılara yer verilmiş, katılımcıların görüşleri MaxQda yazılımıyla görselleştirilerek sunulmuştur.

Lincoln ve Guba (1985) nitel bir çalışmanın geçerlik ve güvenirliğini sağlamak için "inandırıcılık, aktarılabilirlik, tutarlılık, teyit edilebilirlik" stratejilerinden de yararlanılabileceğini ifade etmiştir. Bu çalışmada inandırıcılığı sağlamak amacıyla alanyazında önerilen ayrıntılı betimleme (Creswel ve Poth, 2016) ve farklı uzmanları araştırma sürecine katma (Merriam, 2013); aktarılabilirliği sağlamak amaciyla doğrudan alıntılara yer verme ve açık, anlaşı1ır bir dil kullanma (Lincoln ve Guba, 1985); tutarlılığı sağlamak amacıyla veri toplama aracını hazırlama, uygulama ve analiz etme sürecini detaylı bir şekilde sunma (Merriam, 2013; Yıldırım ve Şimşek, 2008); teyit edilebilirliği sağlamak amacıyla ise bulgu, yorum ve sonuçların verilerle desteklenmesi yöntemlerinden yararlanılmıştır (Creswel ve Poth, 2016).

\section{Araşturma Etiği}

Araştırmada yürütülen sürecin Çukurova Üniversitesi Sosyal ve Beşerî Bilimler Alanında Bilimsel Araştırma ve Yayın Etiği Kurulunca (20.10.2020 tarihli ve E.30821 sayılı) etik açıdan herhangi bir sakınca taşımadığına oy birliği ile karar verilmiştir.

\section{Bulgular}

$\mathrm{Bu}$ bölümde ilkokul öğrencilerine yönelik EBA TV 'de yayınlanan eğitime ilişkin sınıf öğretmenlerinin görüşlerinden elde edilen bulgulara yer verilmiştir. Bulguların analizinde kullanılan sembollere ilişkin açıklamalar Tablo 2'de tanıtılmıştır. 
Tablo 2

Bulguların Analizinde Kullanılan Sembollerin Anlamları

\begin{tabular}{ll}
\hline Sembol & Anlamı \\
\hline & Temayı ifade eder. \\
& Kodu ifade eder. \\
Doğrudan alıntıları ifade eder.
\end{tabular}

Tablo 2'de görüldüğü gibi tema, kod ve alıntılar farklı sembollerle gösterilerek bulguların açık ve anlaşılır olması hedeflenmiştir.

\section{Kullanılan Yöntem ve Tekniklerin Etkililiğine İlişkin Kod ve Tema Yapısı}

EBA TV'de ders anlatımı yapan öğretmenlerin süreç içerisinde kullandıkları yöntem ve tekniklerin etkili olup olmadığına ilişkin katılımcı görüşleri Şekil 1'de sunulmuştur.

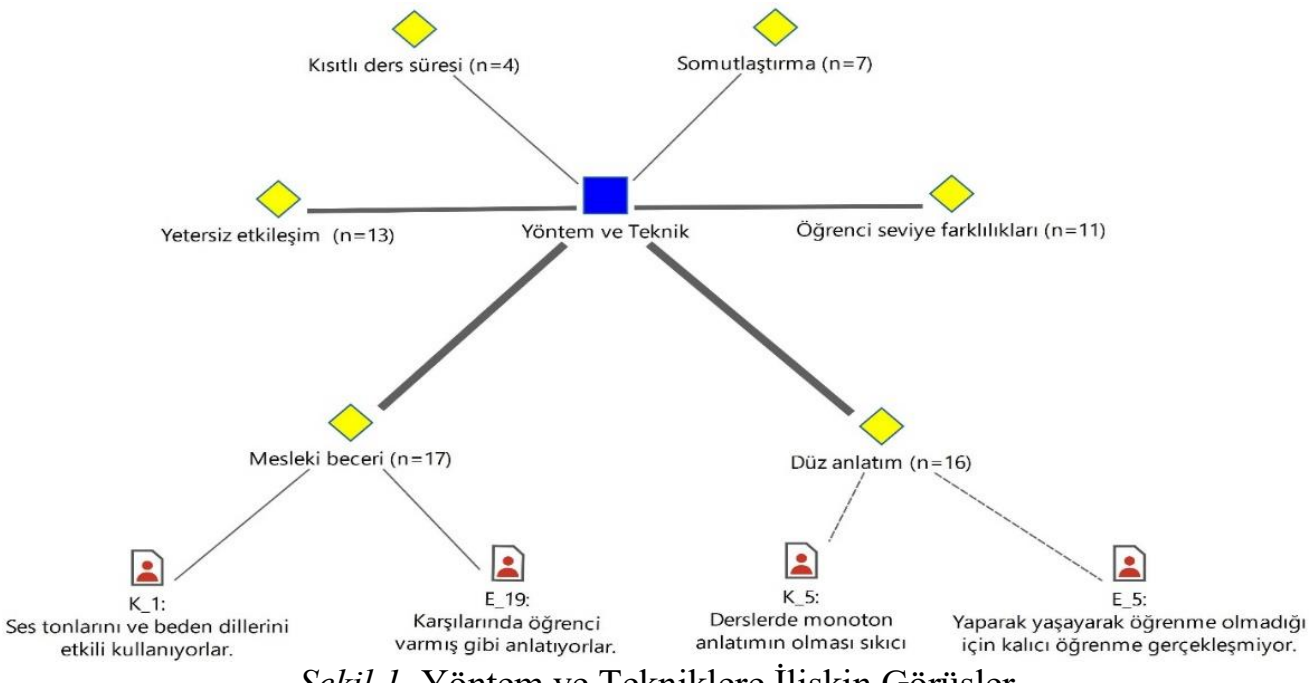

Şekil 1. Yöntem ve Tekniklere İlişkin Görüşler

Şekil 1'de görüldüğg̈ gibi EBA TV de öğretmenlerin kullandığ1 yöntem ve tekniklere ilişkin Kısıtlı ders süresi, Somutlaştırma, Öğrenci seviye farklılıklarl, Düz anlatım, Mesleki beceri, Yetersiz etkileşim olmak üzere altı farklı kod ortaya çıkmıştır. Katılımcıların görüşleri içerisinde en fazla "Mesleki Beceri ve Düz Anlatım" kodları öne çıkmış ve bunlara ilişkin dikkat çeken ikişer alıntıya yer verilmiştir.

\section{Kazanımlara İliş̧kin Oluşan Kod ve Tema Yapısı}

EBA TV'de işlenen dersler sonucunda öğrencilerin kazanımlara ulaşıp ulaşmama nedenlerine ilişkin katılımcı görüşleri Şekil 2'de sunulmuştur. 


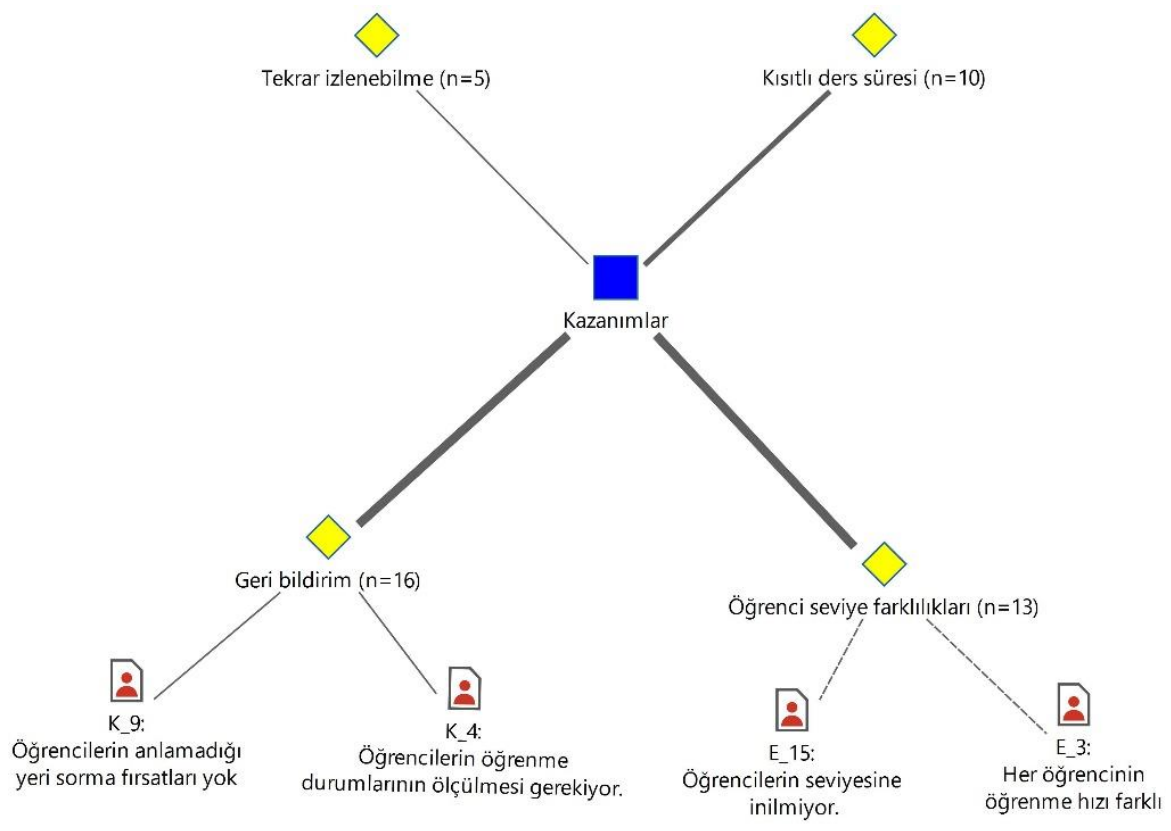

Şekil 2. Kazanımlara İlişkin Görüşler

Şekil 2'de görüldüğü gibi EBA TV de işlenen deslerde kazanımlara ulaşıp ulaşmama nedenlerine ilișkin Tekrar izlenebilme, Klsıtlı ders süresi, Öğrenci seviye farklılıkları, Geri bildirim olmak üzere dört farklı kod ortaya çıkmıştır. Katılımcıların görüşleri içerisinde "Öğrenci Seviye Farklılıkları ve Geri bildirim" kodları öne çıkmıştır. Bunlara ilişkin dikkat çeken ikişer alıntıya yer verilmiştir.

\section{Derslerin Etkisini Artırmaya Yönelik Önerilere İlişkin Oluşan Kod ve Tema Yapısı}

EBA TV'de işlenen derslerin etkililiğini artırmaya yönelik önerilere ilişkin katılımcı görüşleri Şekil 3'te sunulmuştur.

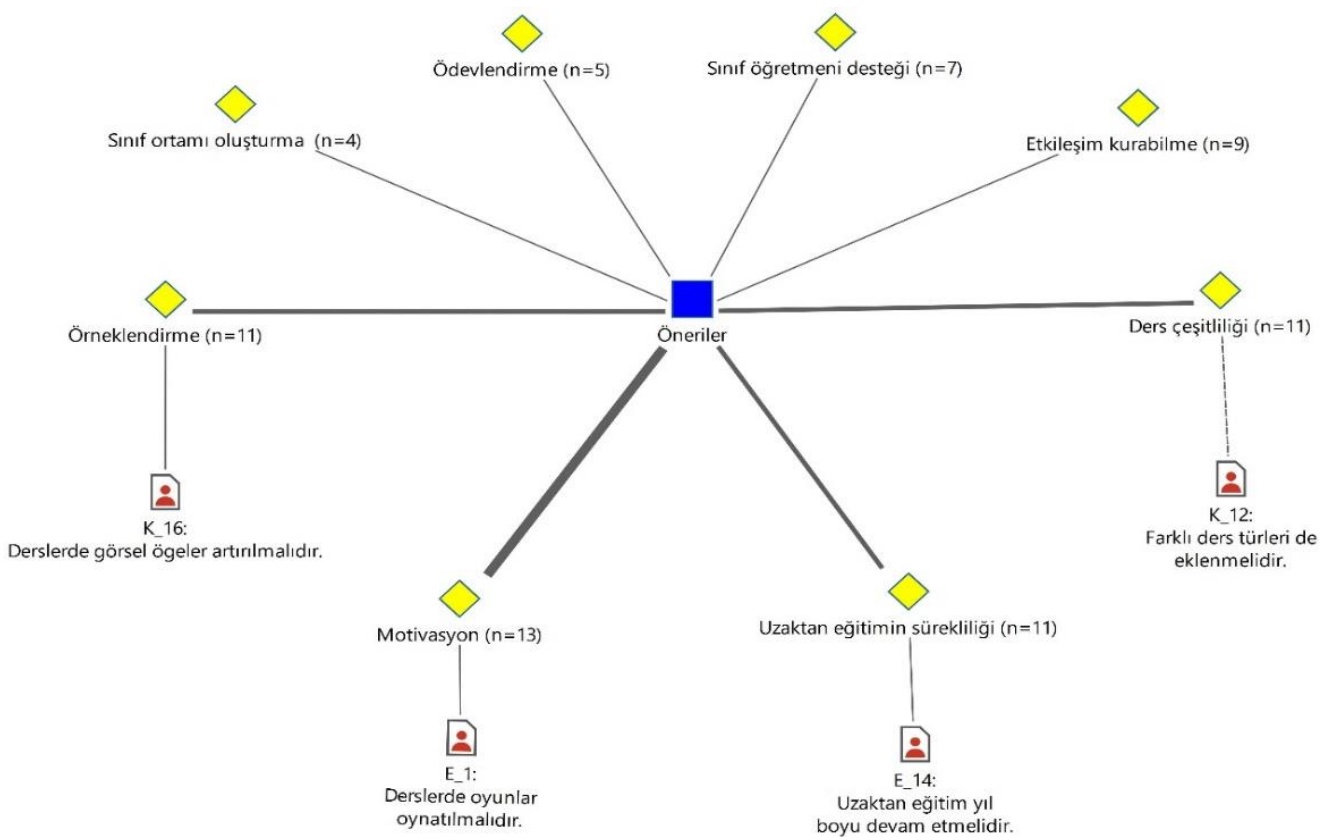

Şekil 3. Derslerin Etkisini Artırmaya İlişkin Öneriler

Şekil 3’te görüldüğü gibi derslerin etkisini artırmaya yönelik önerilere ilişkin Sınıf ortamı oluşturma, Ödevlendirme, Sinıf öğretmeni desteği, Etkileşim kurabilme, Ders çeşitliliği, Uzaktan 
ę̆itimin sürekliliği, Motivasyon ve Örneklendirme olmak üzere toplam sekiz kod ortaya çıkmıştır. Katılımcıların görüşleri içerisinde en fazla "Motivasyon, Uzaktan eğitimin sürekliliği, Ders çeşitliliği ve Örneklendirme" kodları öne çıkmıştır. Bunlara ilişkin dikkat çeken birer alıntıya yer verilmiştir.

\section{Ölçme Değerlendirmeye İlişkin Oluşan Tema ve Kod Yapısı}

EBA TV'de işlenen dersler sonucunda öğrencilerin kazanımlara ulaşıp ulaşmadığını ölçebilmeye ilişkin katılımcı görüşleri Şekil 4'te sunulmuştur.

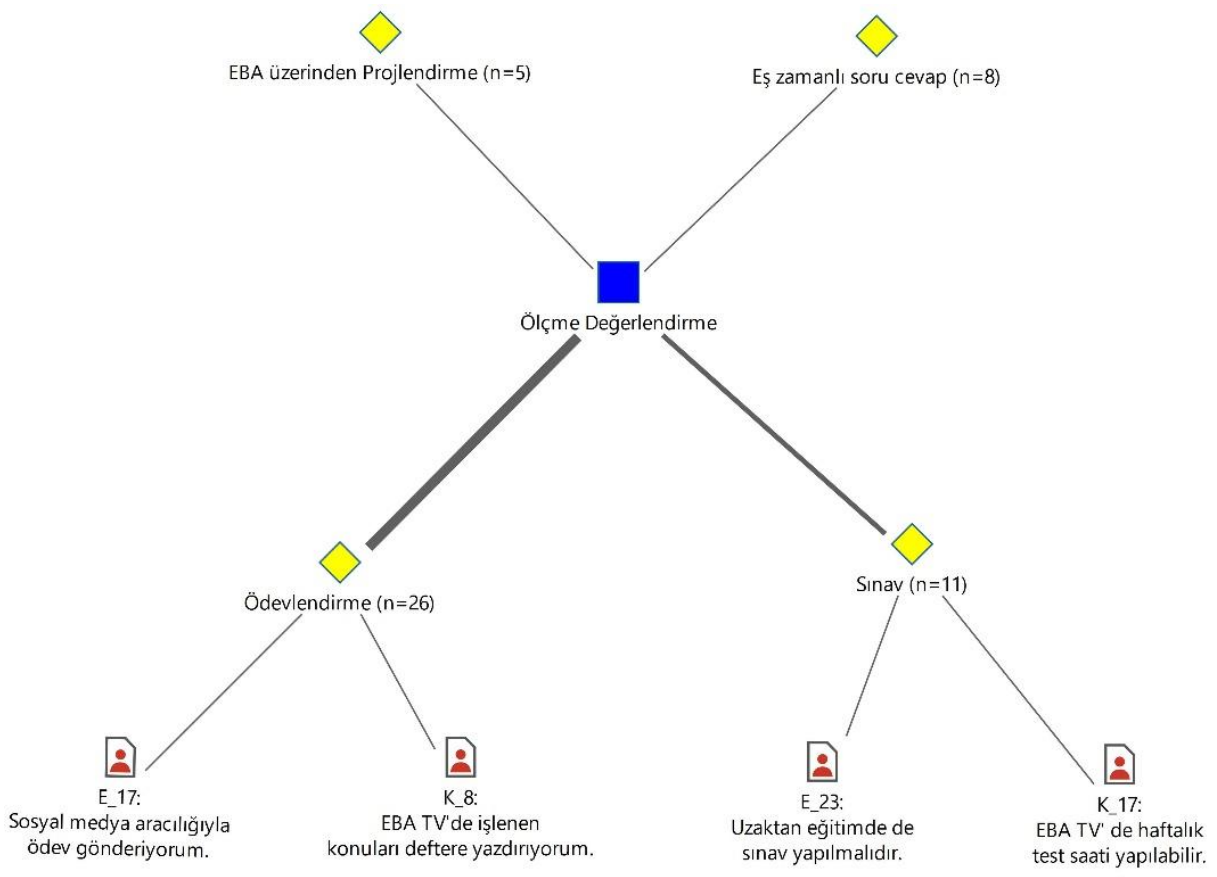

Şekil 4. Ölçme Değerlendirmeye İlişkin Görüşler

Şekil 4'te görüldüğü gibi öğretmenlerin ölçme değerlendirme amacıyla uyguladıkları ve uygulanmasını önerdikleri düşüncelere ilişkin EBA üzerinden projelendirme, Eş zamanlı soru cevap, Ödevlendirme ve Sinav olmak üzere toplam dört kod ortaya çıkmıştır. Katılımcıların görüşleri içerisinde en fazla "Ödevlendirme ve Sınav" kodları tekrarlanmıştır. Bunlara ilişkin dikkat çeken ikişer alıntıya yer verilmiştir.

\section{Sonuç, Tartışma ve Öneriler}

$\mathrm{Bu}$ araştırmanın amacı, Türkiye'de Covid-19 pandemisi nedeniyle örgün eğitime ara verilip uzaktan eğitime geçilmesiyle birlikte EBA TV üzerinden yapılan eğitime ilişkin sınıf öğretmenlerinin görüşlerini değerlendirmektir. $\mathrm{Bu}$ amaç doğrultusunda araştırmaya katılan sınıf öğretmenlerinin yayınlanan derslerde kullanılan yöntem ve tekniklere, öğrencilerin kazanımlara ulaşma durumuna, derslerin etkisinin nasıl artırılabileceğine, derslerdeki ölçme değerlendirmeye ve sürece ilişkin görüşleri incelenmiștir.

Araştırma sonuçlarına göre EBA TV de kullanılan yöntem ve tekniklerin etkili olup olmadığına ilişkin cevaplar incelendiğinde "mesleki beceri" ve "düz anlatım" kodları öne çıkmıştır. Katılımcılar, öğretmenlerin ders anlatırken mesleki becerilerini kullanarak öğrencilerle konuşma havasında dersi anlattıklarını ve bu sayede dersin somutlaştııılmasına katkı sağladıklarını düşünmektedir. Bulguyu destekler nitelikte olan Yenilmez ve Duman (2008) yaptıkları araştırmada ders anlatım esnasında öğretmenin kullandığı dilin, yöntem ve tekniğin öğrencilerin dersi anlamasını etkileyen önemli faktörler arasında olduğunu vurgulamıştır. Ayrıca Demirel (2000) yaptı̆̆ı çalışmada etkili öğretmenin özelliklerinden birinin iş bilirlik olduğunu belirterek mesleki becerinin önemine değinmiştir. Buradan hareketle, uzaktan eğitimi etkili kılan baş aktörün öğretmen olduğu söylenebilir. Böylece öğretmenin 
etkili anlatımı, öğrencinin istek ve ihtiyacını öngörmesi ve çeşitli materyallerden yararlanarak dersi somutlaştırmasının uzaktan eğitimin etkililiğini artıracağı söylenebilir.

Katılımcılar, televizyon karşısında öğrencilerin pasif dinleyici olması ve derslerde sadece düz anlatımın olmasından dolayı uzaktan eğitimi verimsiz olarak görmektedirler. Bunu destekler nitelikte olan Fidan (2008) yaptığı araştırmada öğrencilerin tam olarak kazanımlara ulaşabilmesi için sınıf ortamında aktif bir şekilde eğitim araçlarından yararlanması gerektiğini vurgulamıştır. Ayrıca Ocak vd. (2015) yaptıkları çalışmada ders işleniş sürecinde sabit yöntem ve teknik kullanımının öğretimi etkisizleştirdiği farklı yöntem ve teknikler kullanılmasının öğretimin niteliğini yükselttiğini belirtmiştir. Buradan hareketle uzaktan eğitim sürecinde kullanılan yöntem ve tekniklerin yapılandırmacı anlayışın aksine öğretmeni aktif öğrenciyi pasif duruma getirdiği söylenebilir. Bu bağlamda EBA TV'de kullanılan materyallerin niteliklerinin yetersiz olduğu ve geliştirilmesine ihtiyaç duyulduğu düşünülmektedir. Bu bulgunun aksini ortaya koyan Salyers, Carter, Barrett ve Williams (2010), inceledikleri uzaktan eğitim çalışmalarında tecrübeli uzman öğreticilerin dersleri yürütmesi nedeniyle kullanılan materyallerin yeterli düzeyde olduğu ve öğretmenlerin derste kullandıkları yöntem ve tekniklerin dersi kolaylaştırıcı bir etkiye sahip olduğunu belirtmiştir. Bu bağlamda Millî Eğitim Bakanlığı (MEB) bünyesinde uzaktan eğitim konusunda deneyimli bir kadronun oluşturulması öğretim uygulamalarının kalitesini yükselteceği düşünülmektedir. Ayrıca verilen cevaplar içerisinde "Yetersiz etkileşim" de öne çıkan ifadeler arasında yer almaktadır. Araştırmaya katılan öğretmenler, uzaktan eğitimin yüz yüze eğitimin yeri tutamayacağını ifade etmişlerdir. Çünkü ilkokul çağındaki öğrencilerin öğretmenle etkileşim içinde duygusal bağ kurduğu zaman öğrenmeye istekli olacağını belirtmişlerdir. Buradan hareketle öğretmen öğrenci etkileşiminin ilkokul çağındaki öğrencilerin öğrenmesini etkileyen önemli değişkenlerden biri olduğu söylenebilir. Buna paralel olarak Ceylan (2008) yaptığı çalışmada, ilkokul öğrenci ve öğretmenleri arasında etkili iletişimin sağlanmasıyla birlikte akademik başarının da yükseldiğini vurgulamıştır.

Araştırma sonuçlarına göre kazanımlara ulaşıp ulaşmama durumuna ilişkin en fazla "öğrenci seviye farklılıkları" ve "geri bildirim" kodları öne çıkmıştır. Katılımcılar nitelikli bir öğretim süreci için ders sonunda öğrenme düzeylerinin ölçülmesi ve öğrencilerin anlamadığı yerleri sorarak geri bildirim alınması gerektiğini belirtmişlerdir. Bulguyu destekler nitelikte olan Kılınç (2015) uzaktan eğitimin sınırlılıkları arasında, öğrencinin öğrenme güçlüğü yaşadığı konularda anında çözüm bulamaması ve sorularına cevap alamamasını vurgulamıştır. Ayrıca katılımcılar öğrenci seviyeleri birbirinden farklı olduğu için herkese tek tip eğitim verilmesinin yanlış olduğunu belirtmişlerdir. Bu bulguya benzer olarak Deveci (2019) yaptığı çalışmada uzaktan eğitimin sorunları arasında birbirinden farklı düzeyde çok sayıda öğrencinin olmasını ifade etmiştir. Bununla birlikte bireysel farklılıklara ilişkin yapılan çalışmalar (Demirbaş ve Demirkan, 2003; Hasırcı, 2006; Musgrove, 2002; Oral, 2003) incelendiğinde, her öğrencinin öğrenme stilinin farklı olabileceği ve öğretim sürecinde buna dikkat edilmesi gerektiği vurgulanmıştır. $\mathrm{Bu}$ bulgunun aksine, $\mathrm{Lu}, \mathrm{Yu}$ ve Yiu (2003) yüksek lisans öğrencileri üzerinden yaptıkları çalışmada, uzaktan eğitimde öğrencilerin farklı öğrenme biçimlerine sahip olmalarının öğretim sürecinde herhangi bir sorun oluşturmadığ 1 ve öğrencilerin eşit düzeyde öğrenme sağladıklarını belirtmişlerdir. Oysa, uzaktan öğretimin, yetişkin eğitimi için uygun yapıda olması, uzaktan eğitim alan yetişkinlerin eğitime katılma amaç ve motivasyonuna sahip olması, öğrenme süreçlerine de olumlu yansıyacaktır. Diğer yandan, temel eğitim kademesinde öğrencilerin yetişkinler düzeyinde sorumluluk üstlenmesi beklenmemekte ve dışsal motivasyon odaklı bir anlayışa sahip olmaktadırlar. Buradan hareketle öğrencilerde öğrenme sorumluluğu geliştirildiğinde uzaktan eğitimin seviye farklılıkları boyutundaki olumsuzluğunun en aza indirgenebileceği düşünülmektedir. Bu bağlamda, uzaktan eğitimin, temel eğitim düzeyinde başarıya ulaşabilmesi için öğrencilerde öncelikle öğrenme sorumluluğunun geliştirilmesi gerektiği söylenebilir.

Araştırmaya katılan öğretmenlerin bir kısmı öğrencilerin kazanımlara rahatlıkla ulaşabileceğini düşünmektedir. Bu düşüncenin altında yatan dayanak ise "tekrar izlenebilme" kodu ile ortaya çıkmıştır. Uzaktan eğitimde öğrenciler kayıtlı dersleri tekrar izleyebildikleri için anlamadıkları konu ve bilgileri yeniden gözden geçirme firsatına sahip olmakta ve kazanımlara ders dışında da ulaşabilmektedir. Bulguyu destekler nitelikte olan Ergüney (2015) ve Yıldız (2011) da eş zamanlı olmayan (asenkron) 
derslerin sürekli tekrar edilebilmesinin, öğrencilere kendi hızında ilerleme ve öğrenme imkânı sağladığını vurgulamıştır.

Araştırma sonuçlarına göre öğretmenlerin EBA TV de işlenen derslerin etkisini artırmaya yönelik önerilerine ilişkin; "motivasyon", "örneklendirme", "ders çeşitliliği” ve "uzaktan eğitimin sürekliliği”" kodlarının öne çıktığı görülmüştür. Katılımcılar, öğrencilerin motivasyon düzeylerinin yüksek olması için ders içerisinde ilgi çekici etkinliklere veya oyunlara yer verilmesinin önemli olduğunu belirtmişlerdir. Bulguyu destekler nitelikte olan Uçgun (2013) tarafından yapılan araştırmada, motivasyonu yüksek öğrencilerin öğrenme sürecinden keyif aldıkları ve başarılarını artırdıkları tespit edilmiştir. Böylece uzaktan eğitim derslerinde motivasyonu artan öğrencinin, başarısının da olumlu yönde destekleneceği düşünülebilir. Bununla birlikte katılımcılar, dersleri anlamakta zorluk yaşayan öğrenciler için örnek sayılarının artırılması gerektiğini ifade etmişlerdir. Bu bağlamda, örneklerin artırılmasının konuların/bilgilerin anlamlandırılmasını sağlayarak öğrencinin kazanımlara ulaşmasına katk1 sağlayacağı ileri sürülebilir. Alanyazında yapılan bazı araştırmalar (Fidan, 2008; Ocak, Islak ve Ocak, 2015; Okatan, 2010) ders içerisinde kullanılan örneklerle birçok duyu organının işe koşulmasının kalıcı izli öğrenme sağladığını vurgulamıştır. Diğer önemli bir bulgu, uzaktan eğitimin, örgün eğitime destek olacak şekilde yıl boyunca sürdürülmesinin yararlı olacağına yöneliktir. Uzaktan eğitim etkinliklerinin niteliğinin her geçen gün arttığını, öğretmen ve öğrencilerin uzaktan eğitim sürecine alışmasıyla verimliliğin arttığını belirtmişlerdir. Özellikle ilk defa kameralar karşısında dersi anlatan öğretmenlerin uzaktan eğitim konusunda gün geçtikçe tecrübe kazanması eğitim öğretim sürecini olumlu etkilediği söylenebilir. Buradan hareketle üniversitelerde öğretmenlik lisans programlarına uzaktan eğitime ilişkin derslerin eklenmesi, öğretmen adaylarının deneyim kazanması açısından önemli olacağı ifade edilebilir. Bununla birlikte daha önceden atanmış öğretmenlere tecrübe kazanmaları için uzaktan eğitimle ilgili MEB tarafından hizmet içi eğitimler düzenlemesinin faydalı olacağı düşünülmektedir.

Öğretmenlerin ölçme değerlendirmeye yönelik görüşleri içerisinde en fazla "ödevlendirme" ve "sınav" kodları öne çıkmıştır. Katılımcılar EBA TV de yayınlanan derslere ilişkin ölçme değerlendirme sürecini ödev göndererek takip ettiklerini belirtmişlerdir. Bununla birlikte öğrencilerine istenen düzeyde geri bildirim verebilmeleri için EBA web adresinde anlatılan konulara yönelik haftalık veya aylık sınav yapılmasının önemli olduğunu vurgulamışlardır. Ayrıca katılımcılar uzaktan eğitimin kendi içerisinde anlık sınav yapabileceği ölçme değerlendirme sisteminin kurulması gerektiğini önermişlerdir. Buna paralel olarak Brannon ve Essex (2001) yaptıkları çalışmada eş zamanlı olmayan eğitimlerde anında dönüt düzeltme yapılmamasının ölçme değerlendirme sürecini aksattığını ifade etmişlerdir. Nitekim Aktaş (2008) yaptı̆̆ ç̧alışmada, eğitim sürecinde ölçme değerlendirmenin eğitim kadar önemli olduğunu vurgulamıştır. Buradan hareketle formal eğitimin olduğu her platformda (örgün veya uzaktan eğitim) ölçme değerlendirmenin de olması gerektiği söylenebilir. Fakat katılımcıların ölçme değerlendirmeye yönelik görüşleri geleneksel yöntemler olan ödev ve sinav etrafinda toplanmıştır. Bunun sebebi, katılımcıların yarıya yakını (\%42) on yıl ve üzeri kıdeme sahip olduğundan yenilikçi ölçme değerlendirme araçlarını kullanmıyor olmalarıyla açıklanabilir. Bulguyla paralel Kanatlı (2008) yaptığ çalışmada genç öğretmenlerin alternatif ölçme değerlendirme araçlarına daha olumlu baktığını vurgulamıştır. Buradan hareketle MEB tarafından özellikle 10 yıl ve üzeri kıdeme sahip öğretmenlere çağdaş ölçme araçlarıyla ilgili hizmet içi eğitimler düzenlemesinin yararlı olacağı söylenebilir.

Sonuç olarak dünyada ve Türkiye'de olağanüstü dönemlerden geçilmesi, uzaktan eğitimi, eğitim sisteminin önemli alternatiflerden biri haline getirmiştir. Ülkemizde eğitim tarihi boyunca ilk defa ulusal anlamda uzaktan eğitime geçilmesi birtakım sorunları da beraberinde getirmiştir. Öğretmen ve öğrencilerin alışık olmadığı bu sistemde özellikle etkileşimin olmaması, bireysel farklılıkların dikkate alınmaması, öğretimde kullanılan yöntem ve tekniklerin yetersiz olması, örneklerin sinırlı olması, ders sürelerinin kısa olması ve ölçme ve değerlendirmenin yapılamaması yaşanan olumsuzluklar arasında sayılmıştır. Fakat bu sorunların uzaktan eğitime uyum sağlamaya başladıkça ortadan kalkacağı beklenmektedir. Nitekim dile getirilen sorunların çoğu eğitmen veya sistem kaynaklıdır. Buradan hareketle öğretmenlerin kendilerini geliştirmesi ve sistemin yeniden düzenlenmesiyle eğitim sürecinin daha işlevsel olacağı söylenebilir. Bu bağlamda araştırma sonuçlarına göre uygulama sürecinin niteliğini arttırmaya ve ileride yapılacak çalışmalara yönelik bazı öneriler sunulabilir: 
- $\mathrm{Bu}$ çalışmada öğretmenlerin büyük kısmının uzaktan eğitim tecrübesi olmadığ1 belirlendiğinden, MEB tarafından öğretmenlere sertifika programları düzenlenerek uzaktan eğitim verebilme yetkinliği arttırılmalıdır.

- Bu çalışmada EBA TV'de ders anlatan öğretmenlerin ders anlatım sürecini farklılaştırmak yerine çoğunlukla düz anlatım yöntemiyle dersi yürüttükleri belirlendiğinden, öğretmenlik lisans programlarına uzaktan eğitimle ilgili seçmeli/zorunlu dersler eklenerek uzaktan eğitimde yöntem ve teknik konusunda bilgilendirici çalışmalar yapılmalıdır.

- Bu çalışmada uzaktan eğitimin yıl boyu devam etmesinin faydalı olacağı belirlendiğinden, uzaktan eğitim dersleri daha da geliştirilip y1l boyunca örgün eğitime destek olarak yayınlanmaya devam etmelidir.

- Bu çalışmada EBA TV'de dersleri takip eden öğrencilerin motivasyon düzeylerinin yüksek tutulmasının önemli olduğu belirlendiğinden, uzaktan eğitim sürecinde zenginleştirilmiş içerikler geliştirilmelidir.

- Yeni yapılacak araştırmalarda; çalışma grubu genişletilerek ilkokul yöneticileri, velileri ve öğrencileri de eklenebilir.

- Yeni yapılacak araştırmalarda; EBA TV'de yayınlanan derslerin ilkokul kademelerine göre ayrı ayrı değerlendirilmesi yapılabilir.

- Yeni yapılacak araştırmalarda; EBA TV'nin diğer kanalları olan ortaokul ve lise kanallarında uygulanan eğitimin değerlendirmesi yapılabilir.

- Yeni yapılacak araştırmalarda; EBA TV'de uygulanan uzaktan eğitime ilişkin program geliştirme çalışmaları yapılabilir.

\section{Yazarların Katkı Oranı}

Bu makaleye birinci yazarın \%50, ikinci yazarın \%50 oranında katkısı vardır.

\section{Çıkar Çatışması}

Çıkar çatışması teşkil edebilecek bir durum yoktur.

\section{Kaynaklar}

Afşar, B. ve Büyükdoğan, B. (2020). Covid-19 pandemisi döneminde İ̈BF ve SBBF öğrencilerinin uzaktan eğitim hakkındaki değerlendirmeleri. Karatay Sosyal Araştırmalar Dergisi, (5), 161182.

Akar, H. (2019). Durum çalışması. A. Saban ve A. Ersoy (Ed.). Eğitimde nitel araştırma desenleri içinde (ss. 139-179). Ankara: Anı Yayıncılık.

Aktaş, C.M. (2008). Öğretmenlerin yeni ortaöğretim matematik öğretim programının ölçme değerlendirme boyutuna baklşlarının incelenmesi. Doktora tezi. Karadeniz Teknik Üniversitesi, Trabzon.

Aydın, E. (2020). Covid-19 döneminde EBA TV üzerinden yapılan Türkçe derslerinin değerlendirilmesi. Milli Ĕgitim Dergisi, 49(1), 877-894.

Bahçeşehir Üniversitesi. (2020, May1s). Uzaktan eğitim süreci üzerine veli, öğretmen ve öğrencilerden elde edilen veriler ile ilgili araştırma bulgularını rapor. https://docs.google.com/document/d/1Yg6DyVDFf_ZwVoMhxislU5ipztqQQm8naNgAEUqz $\mathrm{yCg}$ /edit?usp=sharing adresinden 20.05.2020 tarihinde erişilmiştir.

Baki, A. (2007). Bilişism ve iletişim teknolojileri karşısında geleceğin üniversiteleri. Aktan, C.C. (Ed.), Değişim çağında yüksek öğretim: Global trendler-paradigmal yönelimler, Yaşar Üniversitesi, İzmir. 
Branon, R. F. and Essex, C. (2001). Synchronous and asynchronous communication tools in distance education: A survey of instructors. Tech Trends, 45(1), 36-42.

Ceylan, G. (2008). Öğretmen-ögrrenci etkileşiminin sınıf atmosferine etkisi (Aksaray ili örneği). Yüksek lisans tezi. Selçuk Üniversitesi Sosyal Bilimler Enstitüsü, Konya.

Coşkunserçe, O. ve İşçitürk, G. B. (2019). Eğitim bilişim ağı (EBA) platformu hakkında öğrencilerin farkındalığının artırılmasına yönelik bir durum çalışması. Eğitimde Nitel Araştırmalar Dergisi, 7(1), 260-276.

Creswell, J. W., and Poth, C. N. (2016). Qualitative inquiry \& research design choosing among five approaches (4. Edition). London: Sage Publications.

Çakın, M. ve Akyavuz, E. K. (2020). Covid-19 süreci ve eğitime yansıması: öğretmen görüşlerinin incelenmesi. International Journal of Social Sciences and Education Research, 6(2), 165-186.

Demirbaş, O. O. ve Demirkan, H. (2003). Focus on architectural design process through learning styles. Design Studies, (24), 437-456.

Doğan, S. ve Koçak, E. (2020). EBA sistemi bağlamında uzaktan eğitim faaliyetleri üzerine bir inceleme. Ekonomi ve Sosyal Araştırmalar Dergisi, 7(14), 110-124.

Elcil, Ş. ve Şahiner, D. (2014). Uzaktan eğitimde iletişimsel engeller. Sosyal ve Beşeri Bilimler Dergisi, 6(1), 21-33.

Ergüney, M. (2015). Uzaktan eğitimin geleceği: MOOC (Massive open online course). Eğitim ve Ögretim Araştırmaları Dergisi, 4(4), 15-22.

Fidan, N. K. (2008). İlköğretimde araç gereç kullanımına ilişkin öğretmen görüşleri. Kuramsal Ĕ̈itimbilim Dergisi, 1(1), 48-61.

Gürer, M. D., Tekinarslan, E. ve Yavuzalp, N. (2016). Çevrimiçi ders veren öğretim elemanlarının uzaktan eğitim hakkındaki görüşleri. Turkish Online Journal of Qualitative Inquiry, 7(1).

Hasırc1, Ö. K. (2006). Sınıf öğretmenliği öğrencilerinin öğrenme stilleri: Çukurova Üniversitesi örneği. Eğitimde Kuram ve Uygulama, 2(1), 15-25.

Işı1k, A. H., Karacı, A., Özkaraca, O. ve Biroğul, S. (2010). Web tabanlı eş zamanlı (senkron) uzaktan eğitim sistemlerinin karşılaştırmalı analizi. Akademik Bilişim, 10-12.

İnci Kuzu, Ç. (2020). Covid-19 pandemisi sürecinde uygulanan ilkokul uzaktan eğitim programı (eba tv) ile ilgili veli görüşleri. Milli Ĕ̈itim Dergisi, 49(1), 505-527.

Kanatl1, F. (2008). Alternatif ölçme ve değerlendirme teknikleri konusunda sinıf öğretmenlerinin görüşlerinin değerlendirilmesi. Yüksek lisans tezi. Mustafa Kemal Üniversitesi, Hatay.

Kılınç, M. (2015). Uzaktan eğitim uygulamalarının etkililiği üzerine bir araştırma (İnönü Üniversitesi uzaktan eğitim merkezi ilahiyat lisans tamamlama programı örneği). Doktora tezi. İnönü Üniversitesi, Malatya.

Merriam, S. B. (2013). Nitel araştırma: Desen ve uygulama için bir rehber (3. Baskıdan Çeviri, Çeviri Editörü: S. Turan). Ankara: Nobel Yayın Dağıtım. 
Miles, M, B., and Huberman, A. M. (1994). Qualitative data analysis: An expanded sourcebook. Thousand Oaks, CA: Sage

Musgrove, A. T., (2002). An examination of the Kolb LSI and geft and their relationship to academic achievement in web-based and face to face nursing courses. Thesis of Florida Athlantic University, Boca Raton, Florida.

Ocak, İ., Islak, F. G. ve Ocak, G. (2015). İlkokul 4. sınıf fen bilimleri dersinde kavram karikatürü kullanımının akademik başarıya etkisi. Bartın Üniversitesi Eğitim Fakültesi Dergisi, 119-132.

Okatan, D. S. (2010). Fen bilgisi eğitiminde modellendirme ve somutlaştırmanın öğrenci başarısına etkisi. Yüksek lisans tezi. Kafkas Üniversitesi, Kars.

Oral, B. (2003). Ortaöğretim öğrencilerinin öğrenme stillerinin incelenmesi. Kuram ve Uygulamada Eğitim Yönetimi, 35, 418-435.

Öztürk, B. ve Çetinkaya, A. (2021). Pandemi döneminde bir eğitim aracı olarak televizyon: TRT EBA TV. INIF E-Dergi, 6(1), 140-162.

Patton, M. Q. (2018). Nitel araştırma ve değerlendirme yöntemleri (3. Baskıdan Çeviri, Çeviri Editörü: M. Bütün ve S.B. Demir). Ankara: Pegem Akademi.

Salyers, V., Carter, L., Barrett, P., and Williams, L. (2010). Evaluating Student and Faculty Satisfaction with a Pedagogical Framework. The Journal of Distance Education, 24(3).

Sünbül, A. M. (2012). Eğitime yeni bakışlar. Konya: Eğitim Yayınevi.

Szente, J. (2020). Live virtual sessions with toddlers and preschoolers amid COVID-19: Implications for early childhood teacher education. Journal of Technology and Teacher Education, 28(2), 373-380.

Şen, B., Atasoy, F. ve Aydın, N. (2010, 10-12 Şubat). Düşük maliyetli web tabanlı uzaktan eğitim sistemi uygulaması. 12. Akademik Bilişim Konferansı Etkinlikleri, Muğla Üniversitesi, Muğla. https://ab.org.tr/kitap/ab10.pdf adresinden 28.10.2021 tarihinde erişilmiştir.

Telli, S. G. ve Altun, D. (2020). Coronavirüs ve çevrimiçi (online) eğitimin önlenemeyen yükselişi. Üniversite Araştırmaları Dergisi, 3(1), 25-34.

Toker Gökçe, A. (2008). Küreselleşme sürecinde uzaktan eğitim, Dicle Üniversitesi Ziya Gökalp Eğitim Fakültesi Dergisi, 11, 1-12.

Uçgun, D. (2013). Türkçe öğretmenlerinin öğrencileri motive etme düzeyleri ile ilköğretim 6. sınıf öğrencilerinin Türkçe dersine yönelik tutumları arasındaki ilişki. Mersin Üniversitesi Eğitim Fakültesi Dergisi, 9(2), 449-460.

Yapıcı, M. (2004). İlköğretim dilbilgisi konularının çocuğun bilişsel düzeyine uygunluğu. İlköğretimOnline, 3(2), 35-41.

Yenilmez, K. ve Duman, Ö. A. (2008). İlköğretimde matematik başarısını etkileyen faktörlere ilişkin öğrenci görüşleri. Manas Üniversitesi Sosyal Bilimler Dergisi, 10(19), 251-268.

Yıldırım, A. ve Şimşek, H. (2008). Sosyal bilimlerde nitel araştırma yöntemleri. Ankara: Seçkin Yayıncilik. 
Yıldız, S. ve Bektaş, F. (2020). EBA TV'de yayınlanan beden eğitimi etkinliklerinin veli ve beden eğitimi öğretmenlerinin görüşleriyle değerlendirilmesi. Milli Eğitim Dergisi, 49(1), 969-987. 


\section{Extended Abstract}

\section{Introduction}

From the past to the present, depending on the changes in the social structure, our understanding of education has changed and developed. While the teacher and the students must be together at the same place and time within the conventional education system, distance education opens some new educational approaches which can be eliminating the same place and the same time requirements. Distance education defined as a type of education in which there is no limitation regarding the time and place (Elcil and Şahiner, 2014). According to Baki (2007), distance education is a method in which the students continue to learn and interact with their teacher in case applying formal education in classrooms is not possible. In recent days, due to the epidemic of Covid-19, formal education was interrupted and distance education has started as compulsory in Turkey. The most important factor in the heart of the decision is that the distance education can be applied asynchronously, regardless of time and place. Thus, the spread of the disease among students and teachers may be prevented and the education process will continue in a healthy and secure way. However, most of the teachers and students faced difficulties in terms of adaption to distance education, which is the "future education system" as they had not' experienced before (Uzaktan Eğitim Raporu, 2020). Telli and Altun (2020) emphasized that in order to achieve success in distance education, it is necessary to change and improve teachers' and students' perceptions towards distance education positively. In this context, determining teachers' current thoughts and perceptions related to distance education may be helpful to succeed within the practice (Bakan and Kefe, 2012). Therefore, the main purpose of the study is to determine the classroom teachers' current views on distance education implemented through the education information network television channel (EBA TV).

\section{Method}

In this study, which was conducted to determine the views of classroom teachers on distance education through EBA TV, a qualitative research method called case study was used. Moreover, to address current problems related to distance education and to reveal the solutions and suggestions and to increase the effectiveness of the courses, and also to determine how to distance education should be implemented in the next period were taken into consideration together. Thus, a single case study design was used in a holistic view. Ensuring maximum diversity has been taken into account in the process of determining the participants. Based on the purpose, the electronic format of the interview form (google form), which has open-ended questions, was prepared and shared via social networks and online communication tools. Classroom teachers who work in public and private primary schools and also follow the EBA TV courses participated in the study $(n=48)$. The data were analyzed through the MaxQda software by implementing the content analysis approach.

\section{Findings}

Two different themes have emerged called "competencies" and "limitations" regarding the methods and techniques used by teachers on EBA TV. While the "competencies" theme includes concretization and vocational skill codes, the "limitation" theme includes inadequate interaction, differences among students' levels, limited course time, and direct instruction codes. On the other hand, differences among students' levels, limited course time, and feedback codes were determined related to situations preventing the students to gain learning goals. Moreover, retrack course record was found as a supportive code in terms of achieving the students learning goals. In the context of teachers' suggestions related to increase effectiveness of the courses on distance education; giving more examples, create a classroom environment, create interaction, teacher support, homework, providing persistence of distance education, increase variety of courses and motivation codes were obtained. Finally, it was found that take-home assignments and project codes have been the most preferred homework type implemented by teachers. Furthermore, teachers suggest simultaneously a question-answer method more during the course. 


\section{Conclusion, Discussion and Recommendations}

Participants thought that teachers use their professional skills to teach the course, during the course time they prefer a conversation style communication with the students to contribute concreteness of the course and the subjects. In parallel with the finding, Yenilmez and Duman (2008) state that the language used by the teacher in the classroom is one of the most important factors which positively affect students' learning. In addition, according to Demirel (2000), one of the most important teacher qualifications is customizing communication style. In this regard, it seems, the main factor that makes the course more effective in distance education is the teacher.

On the other hand, due to students' passive role in front of the TV or monitor and they seem like audiences. Thus, the teacher-centered direct instruction method is more dominant. For this reason, the courses on distance education have been ineffective. Fidan (2008) emphasizes that in order to gain learning goals, students should be active and they should use instructional tools and materials in the classroom environment. Moreover, according to the teachers' views, in a qualified teaching process, students' learning levels should be measured at the end of each course and immediate feedback should be obtained by asking questions whether students gained the learning outcomes or not. However, Kiliç (2015) express that inabilities giving immediate feedback, suggestions about learning problems and difficulties to students are in the limitations of distance education. While the teachers mention that they follow the students learning process on homework assignments regarding measurement and evaluation, they emphasize the importance of weekly and/or monthly tests-quizzes in order to give satisfactory feedback to students. Furthermore, the importance of measurement and evaluation activities in the instruction processes has been ignored (Aktaş, 2008). Therefore, it can be asserted that measurement and evaluation activities must be embedded in to distance education system; however, most of the teachers use conventional measurement methods such as homework and test as they have not enough information about alternative techniques.

Based on the research results, some proposals were presented below.

- Related to distance education, in-service courses and the programs should be provided for teachers by Ministry of National Education (MEB),

- Related to distance education, some courses should be provided into the pre-service teacher education curriculum.

- Distance education should be used as a supportive part of formal education system during the year.

- A research should be conducted by expanding the size and the variety of the participants (e.g. teachers, parents and school directors) 